\title{
Laparoscopic Totally Extra-peritoneal Hernioplasty versus Lichtenstein Open Tension Free Mesh Repair for Inguinal Hernia
}

\author{
Sherif E. Sayed ${ }^{1}$, Ibrahim E. Zayat ${ }^{2}$, Haitham G. Abd El Hady², Osama A. Abdulraheem ${ }^{3}$ \\ ${ }^{1}$ Department of Surgical Oncology, Faculty of Medicine, Beni Suef University, Egypt \\ ${ }^{2}$ Department of General surgery, Faculty of Medicine, Aswan University, Egypt \\ ${ }^{3}$ Department of General Surgery, Faculty of Medicine, Sohag University, Egypt \\ *Corresponding author: Sherif E. Sayed, Mobile: (+20)1119335527, Email: sherifelprincesayed@ yahoo.com
}

\begin{abstract}
Background: Surgery for a groin hernia is the most common operation in general surgery. The recurrence rate in non-specialized centres is high, and postoperative pain and discomfort are common. The inguinal hernia repair has been a controversial area in surgical practice ever since it was associated with recurrence rates which have decreased because of the use of prosthetic mesh.

Objective: This study was aimed to evaluate the benefits and harms of the total extra-peritoneal technique compared with the Lichtenstein technique for inguinal hernia repair.

Patients and Material: This randomized controlled trial study included a total of 40 male patients aged between 14 and 60 years with unilateral or bilateral inguinal hernia, attending at Outpatient Clinic, Aswan University Hospital and followed up there. This study was conducted period from August 2017 to August 2018. They were randomly divided into two groups; Group A Open Lichtenstein hernioplasty and Group B; laparoscopic total extraperitoneal hernioplasty (TEP).

Results: There was a statistically significant difference between Groups A and B cases as regard operative time and hospital stay. There was no statistically significant difference between Group A and B cases as regard intraoperative/postoperative complications. Also, there was no s statistically significant difference as regard VAS, recurrence in either group during the follow- up period of 6 months.

Conclusions: It could be concluded that laparoscopic total extraperitoneal hernioplasty yielded better results regarding operative time and hospital stay. Yet, better results were found regarding complications, but the study could not detect statistical differences.
\end{abstract}

Keywords: Inguinal Hernia Surgery, TEP, Laparoscopic, Lichtenstein hernioplasty.

\section{INTRODUCTION}

Groin hernia surgery is the most common operation in general surgery ${ }^{(\mathbf{1})}$. Inguinal hernia repair has been a controversial area in surgical practice ${ }^{(2)}$. There are multiple factors to this debate ${ }^{(3)}$. The totally extra peritoneal procedure (TEP) combines the advantage of tension-free mesh reinforcement with those of laparoscopy ${ }^{(4)}$. Surgeons can use endoscopy for primary repair if they were sufficiently experienced ${ }^{(5)}$. TEP repair resulted in fewer complications and earlier recovery but is more expensive ${ }^{(\boldsymbol{6})}$. A randomized controlled trial found that postoperative pain after TEP was $3.3 \%$ vs. $9 \%$ for open ${ }^{(7)}$.

The aim of the current work was to compare the most common technique for open mesh repair (Lichtenstein) with total extra peritoneal, TEP technique for the surgical correction of inguinal hernia, and to tell which procedure is safer with less complications.

\section{PATIENTS AND METHODS}

This randomized controlled trial study included a total of 40 male patients aged between 14 and 60 years with unilateral or bilateral inguinal hernia, attending at Outpatient Clinic, Aswan University Hospital and followed up there. This study was conducted period from August 2017 to August 2018.

\section{Ethical approval:}

An approval of the study was obtained from Aswan University academic ethical committee.

Exclusion criteria included patients whose risks outweighs benefits in laparoscopic surgery (heart failure, respiratory failure, pulmonary hypertension, psychologically disturbance), patients who have underwent previous abdominal Surgeries (Pfannenstiel, lower midline abdominal incisions below the umbilicus on the same side of the hernia, also those with previous lower abdominal irradiation, patients with recurrent hernia, complicated inguinal hernia, direct hernia and Obesity $(\mathrm{BMI} \geq 30)$.

\section{Recruitment and randomization:}

All eligible patients scheduled for surgery were briefly informed about the study during the outpatient visit. If interested, patients were then informed in detail by study physician and inclusion and exclusion criteria are verified. For each patient, written informed consent was essential prior to inclusion into the study after extensive information about the intent of the study, the study regimen, potential associated risks, and side effects.

The included subjects were randomly divided into two equal groups; Group A consisted of 20 patients underwent open Lichtenstein hernioplasty and Group B consisted of 20 patients 20 patients 
underwent laparoscopic total extraperitoneal (TEP) hernioplasty).

\section{Operative technique:}

- Laparoscopic TEP repair with mesh: At the end of the dissection, the preperitoneal space should have been fully opened from just across the midline medially to well lateral to the deep ring and well below the ring. The cord is also separated from the abdominal wall to allow space for the lower edge of the mesh. Mesh Insertion: After completing dissection, standard polypropylene mesh measuring $15 \mathrm{~cm} \times 15 \mathrm{~cm}$ was modified and slit laterally, then folded and placed down the $10 \mathrm{~mm}$ port. Usually, part of the mesh remained in the port and the telescope was used to nudge it out into the preperitoneal space. The mesh was carefully unfolded so that its medial edge just crosses the midline, its lateral edge was well lateral to the deep ring hugging the cord and its lower edge was well below the ring at the peritoneal reflection.

- Tension free Lichtenstein hernioplasty: The place for entering the preperitoneal space should be just along the lateral edge of the rectus muscle and just cranial to Cooper's ligament, thus as medial and caudal as possible in the operative field. This is to avoid a conflict with the iliac vessels. Be careful not to make the perforation too large as this will increase the risk of mesh displacement and thereby the risk of hernia recurrence. The Onflexmesh is cut, and the tails are placed around the spermatic cord.

\section{Parameters assessed:}

Certain parameters were assessed during the operative, postoperative and follow- up periods for evaluating the procedure, its consequences and benefits including:

Intra-operative parameters:

- Operative time (in minutes).

- Intra-operative complications.

- Postoperative parameters (within the hospital stay): Postoperative pain. Using the visual analogue scores (VAS), the postoperative pain assessment was done in the first postoperative day six hours after last analgesic dose administration at rest. Patients were asked to describe their pain levels and ten points score was done visual analogue score (VAS) was documented as follows: $0=$ no pain, $10=$ maximum pain ${ }^{(8)}$.

- Before discharge, all patients received the same postoperative instructions (limitation on heavy weightlifting for 4 weeks) and were encouraged to return to normal activities as soon as possible.

- Follow-up parameters: Patients were assessed at first postoperative week in the outpatient clinic for surgery in Aswan university hospital for the presence of early postoperative complications. (Scrotal edema or hematoma, wound seroma or infection and urinary retention).
- Patients were asked to declare their total intake of oral analgesics during the first week after surgery and number of tablets consumed is confirmed from the strips of medications. This is correlated with their activity in the first postoperative week.

- In addition, VISUAL ANALOGUE SCORE was repeated at the 7 thpostoperative day after ensuring that patients stopped analgesia six hours before coming to outpatient clinic (VRS7).

- The degree of limitation of physical activity was assessed at the 7thpostoperative day by asking the patient to perform three simple tests: climbing stairs (3steps), squatting, and rising from a bed. Unrestricted activity was graded as 1 some restriction as 2, and great difficulty as 3 points. The tests were combined into a physical activity index score called the functional limitation score (FLS7) (range 3-9 points) ${ }^{(9)}$.

- Patients were reassessed at 1, 3, and 6 months postoperatively mainly for chronic pain and recurrence.

- Chronic groin pain was defined as groin pain of any type or severity (including testicular or foreign body sensation at the groin) persisting more than three months after the operation ${ }^{(\mathbf{1 0})}$.

- Recurrence is defined as a palpable hernia or a clear defect of the abdominal wall during the first postoperative year. In the event of doubt, recurrence was confirmed by radiologic study to differentiate it from haematoma or seroma.

- Follow up for 6 months to detect the differences between the 2 groups focusing on VAS7, FLS7, chronic pain and recurrence.

\section{Statistical analysis}

Data were verified, coded by the researcher, and analyzed using SPSS version $24^{(11)}$. Descriptive statistics: Means, standard deviations, medians and percentages were calculated. Test of significances: chi-square or Fisher's Exact test was used to compare the difference in distribution of frequencies among different groups. For continuous variables, independent t-test analysis was carried out to compare the means A p-value $<0.05$ was considered significant.

\section{RESULTS}

The study was performed at Aswan university hospital and included 40 patients aged between 14 and 60 (with a mean of $42.5 \pm 12.3$ ) years, all of them were men which reflects the male predominance for this disease. Half of patients were smokers. Four patients (10\%) suffered from COPD and one (3.3\%) had chronic liver disease. All patient conditions were controlled preoperatively. Regarding ASA score, 32 patients $(80 \%)$ were ASA I while the remaining 8 (20\%) patients were ASA II. BMI of the study group ranged between 18 and 32 with a mean of $24.9 \pm 2.45$ $\mathrm{Kg} / \mathrm{m} 2$. Respecting type and site of hernia, in Group 
A: $18(90 \%)$ had unilateral inguinal hernia and two patients $(10 \%)$ had bilateral hernias.

All cases of hernias $(100 \%)$ were direct and indirect inguinal hernias. For Group B: All patients $(100 \%)$ had unilateral inguinal hernia, primary cases with direct and indirect inguinal hernias. For operative time: Group A: the mean operative time was $62 \pm 16$ minutes. In unilateral primary cases, operative time range from 60 - 65 minutes, according to the difficulty of the case, and the occurrence of intra- operative complications. In Group B: it was $65 \pm 29.28$ minutes. In all cases, operative time ranged from $91-149$ minutes, according to the difficulty of the case, and the occurrence of intra-operative complications. There was insignificant difference between Groups as regard operative time being longer in group B (Table 1).

Table (1): Description and Comparison between both study groups as regards operative time

\begin{tabular}{lccc}
\hline & $\begin{array}{c}\text { Group A } \\
(\mathbf{n = 2 0})\end{array}$ & $\begin{array}{c}\text { Group B } \\
(\mathbf{n = 2 0})\end{array}$ & $\begin{array}{c}\text { P- } \\
\text { value }\end{array}$ \\
\hline Operative & $62.00 \pm$ & $65.00 \pm$ & $0.096^{*}$ \\
Time/minute & 16.1 & 29.3 & \\
\hline
\end{tabular}

*Independent t-test was used to compare the mean difference between groups

For intra-operative complications, the overall rate in group A patients was 5\% while in group B it was $10 \%$. All differences are not statistically significant (Table 2).

Table (2): Intraoperative complications in Group $A$ and $B$

\begin{tabular}{lccc}
\hline & $\begin{array}{c}\text { Group A } \\
(\mathbf{n = 2 0})\end{array}$ & $\begin{array}{c}\text { Group B } \\
(\mathbf{n = 2 0})\end{array}$ & $\begin{array}{c}\text { P- } \\
\text { value* }\end{array}$ \\
\hline $\begin{array}{l}\text { Vascular } \\
\text { injuries }\end{array}$ & $1(5 \%)$ & $0(0 \%)$ & 0.415 \\
\hline $\begin{array}{l}\text { Peritoneal } \\
\text { tear }\end{array}$ & $0(0 \%)$ & $2(10 \%)$ & 0.246 \\
\hline $\begin{array}{l}\text { Bowel } \\
\text { injuries }\end{array}$ & $0(0 \%)$ & $0(0 \%)$ & 1.000 \\
\hline $\begin{array}{l}\text { Bladder } \\
\text { injury }\end{array}$ & $0(0 \%)$ & $0(0 \%)$ & 1.000 \\
\hline
\end{tabular}

*Fisher's exact test was used to compare the frequency differences.

Regarding postoperative complications, there was no significant difference between group A and B as regards postoperative complications except that group A had more time for return of normal bowel habits and sounds due to its intra-abdominal manipulations which lead to self-resolved paralytic ileus in one of the cases. and group B two patients encountered subcutaneous emphysema reaching the penis but resolved spontaneously (Table 3).

Table (3): Early postoperative complications in Group A vs. Group B

\begin{tabular}{ccc}
$\begin{array}{c}\text { Group A } \\
(\mathbf{n}=\mathbf{2 0})\end{array}$ & $\begin{array}{l}\text { Group B } \\
(\mathbf{n}=\mathbf{2 0})\end{array}$ & P-value* \\
\hline
\end{tabular}

\begin{tabular}{lccc}
\hline $\begin{array}{l}\text { Wound } \\
\text { seroma }\end{array}$ & $3(15 \%)$ & $1(5 \%)$ & 0.198 \\
\hline $\begin{array}{l}\text { Wound } \\
\text { infection }\end{array}$ & $1(5 \%)$ & $0(0 \%)$ & 0.415 \\
\hline Recurrence & $2(10 \%)$ & $0(0 \%)$ & 0.285 \\
\hline $\begin{array}{l}\text { Peritoneal } \\
\text { tear }\end{array}$ & $0(0 \%)$ & $4(20 \%)$ & $\mathbf{0 . 0 0 2}$ \\
\hline $\begin{array}{l}\text { Ing-scrotal } \\
\text { edema }\end{array}$ & $2(10 \%)$ & $1(5 \%)$ & 0.169 \\
\hline $\begin{array}{l}\text { Delayed } \\
\text { bowel } \\
\text { movements }\end{array}$ & $2(10 \%)$ & $0(0 \%)$ & 0.285 \\
\hline $\begin{array}{l}\text { Subcutaneous } \\
\text { Emphysema }\end{array}$ & $0(0 \%)$ & $2(10 \%)$ & 0.285 \\
\hline $\begin{array}{l}\text { Injectable } \\
\text { analgesic } \\
\mathbf{1 6} \text { hours }\end{array}$ & $2(10 \%)$ & $20(100 \%)$ & $<\mathbf{0 . 0 0 1}$ \\
$\begin{array}{l}\text { 16- 24 } \\
\text { hours }\end{array}$ & $3(15 \%)$ & $9(45 \%)$ & $\mathbf{0 . 0 2 5}$ \\
$\begin{array}{l}\mathbf{2 4}-\mathbf{3 2} \\
\text { hours } \\
>\mathbf{3 2} \text { hours }\end{array}$ & $9(45 \%)$ & $6(30 \%)$ & 0.237 \\
\hline
\end{tabular}

*Fisher's exact test was used to compare the frequency differences.

Table 4 showed the postoperative complications. Pain was assessed on VAS score. In both groups pain scores were higher at the first eight hours after surgery, Group A was associated with lower VAS score in the first 8 hours. Also, there was significant difference between Group A and B as regard VAS at 1st 32 hours postoperative. Likewise, significant difference was found between Group A and $\mathrm{B}$ cases regarding VAS at 7 th postoperative day and in all subgroups. It appears that TEP procedure was well tolerated with satisfactory pain levels. Most of the patients are pain-free at the first postoperative visit after one week.

There was a highly significant difference between Group A and B cases as regard total oral analgesic dose consumption for first week. Group A was more than group B as regards hospital stay mainly related to postoperative complications and return of normal bowel movements which was longer time in group A due to a single case that required more than two days to return to normal bowel (a case of ileus) which resolved spontaneously. No groin persistent pain was detected in both groups, all of the study groups patients experienced pains in first postoperative week and then disappeared completely with no residual pains or foreign body sensations in the groin region. As well, recurrence was reported in only two cases among group A during the follow- up period of 6 months.

Table (4): Postoperative complications in Group A vs. Group B 


\begin{tabular}{lccc}
\hline & $\begin{array}{c}\text { Group A } \\
(\mathbf{n = 2 0})\end{array}$ & $\begin{array}{c}\text { Group B } \\
(\mathbf{n = 2 0})\end{array}$ & $\begin{array}{c}\text { P- } \\
\text { value* }\end{array}$ \\
\hline $\begin{array}{l}\text { VAS score } \\
(\text { Mean } \pm \text { SD })\end{array}$ & & & \\
$\bullet \mathbf{8}$ hrs & $4.8 \pm 1.18$ & $6.13 \pm 0.87$ & $\mathbf{0 . 0 4 1}$ \\
$\bullet \quad \mathbf{1 6}$ hrs & $4.7 \pm 1.65$ & $4.13 \pm 1.4$ & 0.448 \\
$\bullet \mathbf{2 4}$ hrs & $3.4 \pm 1.37$ & $3.3 \pm 1.29$ & 0.322 \\
$\bullet \quad 32 ~ \mathbf{~ h r s}$ & $2.4 \pm 1.03$ & $2.06 \pm 1.46$ & 0.164 \\
• $\mathbf{7}^{\text {th }}$ Day & $2.00 \pm 0.25$ & $1.25 \pm 0.4$ & 0.058 \\
\hline $\begin{array}{l}\text { Oral } \\
\text { Analgesic in }\end{array}$ & $496.00 \pm$ & $400.00 \pm$ & $\mathbf{0 . 0 0 1}$ \\
$\mathbf{1}^{\text {st }}$ week & 64.2 & 80.4 & \\
\hline $\begin{array}{l}\text { Hospital } \\
\text { Stay/days }\end{array}$ & $2.10 \pm 0.3$ & $1.00 \pm 0.1$ & $\mathbf{0 . 0 2 1}$ \\
\hline
\end{tabular}

*Fisher's Exact test was used to compare the frequency differences.

\section{DISCUSSION}

The current study was performed at Aswan university hospital. The mean operative time in open Lichtenstein group was $62 \pm 16$ minutes, consistent with Dinko et al. ${ }^{(12)}$ who reported that the mean operative time among open Lichtenstein group was $57.2 \pm 17.8$ minutes. In the TEP group the mean operative time was $92 \pm 29.28$ minutes. It was longer than most other studies that ranged from 45 to 58.4 minutes due to our new experience in such cases (13-16).

Schouten et al. ${ }^{(17)}$ described a rather long learning curve of endoscopic TEP hernia repair; that even after more than 400 individually performed TEP procedures; there is still progress in reducing the conversion rate, incidence of short-term postoperative complications, and operative time. An important reason that surgeons are hesitant to fully accept TEP hernia repair is its longer learning curve.

The overall intraoperative complication was found to be similar in both groups $5 \%$. The most common intraoperative complication was bleeding that occurred in $2.5 \%$ of cases in group A. In TEP group bleeding was not significant and was controlled successfully using diathermy. Bleeding from inferior epigastric vessels is one of the most common sources encountered. It is critical to identify the inferior epigastric vessels behind the rectus muscles and these vessels are best left adhered to them during dissection of the preperitoneal space. It is a key landmark of the groin, as it separates the direct and indirect inguinal hernia defects. Dissecting the inferior epigastric vessels off the rectus muscles will cause more bleeding during the procedure and makes placement of the mesh difficult ${ }^{(18)}$.

In about $25 \%$ of the cases, aberrant obturator vessels are present and could lead to unexpected bleeding if not properly recognized ${ }^{(\mathbf{1 9})}$. Those vessels are branches from inferior epigastric vessels and pass over the superior pubic ramus to reach the obturator foramen, so good understanding of the anatomy protects against injury of this dangerous vessels ${ }^{(20)}$. Our study did not encounter any major vessels injuries including external iliac and deep circumflex iliac vessels, due to proper identification of the triangle of doom and better skills of working surgeons at our hospitals. Visceral injury did not occur in our study due to better learning curve and skills. This trivial visceral injury and absence of urinary bladder injuries in accordance with most studies that considers laparoscopic approach safe and feasible (21) and against the earlier disappointing results that is believed to be related to the early phase of learning curve.

In this study, postoperative complications were encountered in $45 \%$ of patients. Those encountered postoperative complications were well controlled and tolerated by our patients. There was no need for a second operative intervention as most complications were managed conservatively reflecting the general safety of the procedures.

Postoperative complications were approximately $50 \%$ of cases in group A and $40 \%$ of cases in group B which was significantly different in favour of TEP group. The most common postoperative complication was inguinoscrotal swelling due to seroma formation which affected $15 \%$ of cases of group A and 5\% of cases in group B. This happened mainly in patients suffering from large hernial sacs including congenital type of inguinal hernia. It was also evident in cases with chronic liver disease. In those patients our technique aimed at limiting the dissection of hernia from the cord by ligating and transecting the hernia and reducing the proximal part while leaving the distal part open. On the contrary, other surgeons thought that this is not necessary, and the dead space will collapse spontaneously after absorption of fluids ${ }^{(22)}$.

The inguinoscrotal seroma resembled recurrent hernia and necessitated ultrasonography in two patients to rule out recurrence. Postoperative pressure dressing and scrotal support was applied together with " $\alpha$-chymotrypsin" injection for three days followed by "Alphintern" for one week. Reassurance and watchful waiting were the basis of treatment. However, in the late cases of our study we started to put a drain in those risky patients with satisfactory results. A recent Cochrane review, of 17 studies assessing the use of prophylactic antibiotics, reported that the overall infection rates were in the range of $3.1 \%$ and $4.5 \%{ }^{(23)}$. None of our patients suffered from deep infections related to the mesh. The deep infection rate is generally rare in the groin and is found to be in the range of $0.3 \%-0.6 \%{ }^{(24)}$.

In the case of TEP, the extraperitoneal space is markedly narrower than the abdominal space and impairs visibility when using current of electrocautery for TEP dissection. Hence, many TEP surgeons avoid 
its use and perform dissection using instead a pulling and counter pulling technique, while tearing the connective tissue bridges between the anatomic structures. That inevitably results in a higher rate of secondary bleeding so according to Köckerling $\boldsymbol{e t}$ al. (25) the use of the current of electrocautery must be recommended for dissection to reduce the secondary bleeding rate but extreme care must be exercised when using this at the level of the peritoneum because this can cause adhesions to the intestines as well as thermal damage.

Early postoperative pain analgesic requirements were higher in initial hours postoperatively in TEP group, however, the scores settled to equal levels after 32 hours of surgery, but group A cases showed lower mean VAS compared to group B cases (5.8 vs 6.13), but those results were proven to be statistically insignificant. None of our patients suffered from unbearable acute postoperative abdominal pain (score of 10). The TEP group patients generally appeared to experience more acute postoperative pain levels when compared to the open group in first 16 to 24 hours. Our results agreed with the findings of study by Lepere et $\mathbf{a l} .{ }^{(26)}$. Nonsignificant difference was found between Group A and B cases regarding VAS at 7thpostoperative day visit in the outpatient clinic. Several factors affect the perception of patients of postoperative pain, including the type of intervention, complications, age, and individual tolerance. Prosthesis fixation methods employed during hernioplasty can result in varying degrees of postoperative pain (27). Mesh fixation is thought to prevent the risk of recurrence due to implant dislocation. It was common to recommend fixation with various stapling devices, but these surgical tacks and clips have been implicated in promoting the development of postoperative inguinal pain ${ }^{(28)}$. Stark et al. ${ }^{(29)}$ demonstrated that reducing the number of clips employed significantly reduces nerve irritation and chronic pain syndromes.

Similarly, postoperative hospital stay was longer in open group compared with the TEP group with a mean of 2.1 vs. 1 days, mainly related to postoperative complications and this was in line with Baca et al. ${ }^{(30)}$. There was a surprisingly large number of studies with very wide range of differences describing the length of hospital stay in the literature. The length of stay, although a good indication of early postoperative outcome and cost, is much more affected by the hospital policy than by the technique. There were greater differences in the mean length of stay between different hospitals than between different operative techniques ${ }^{(31)}$. The rate of return to normal physical activity is one of the famous parameters to express the outcome of many surgical operations. However, it has many limitations including patients' preoperative activity, psychological and mental status, age, sex, and socioeconomic state. The results were unsurprisingly in favour of the TEP group compared to group A (4.74 vs3.94) and this agreed with result of Lepere et al. ${ }^{(26)}$ and Baca et al. ${ }^{(30)}$.

The definition of chronic pain is any type of pain or discomfort which lasts for more than three months postoperatively ${ }^{(32)}$. According to this definition, none of our patients suffer from chronic pain. However, we had one patient of group (A) suffering from nonspecific groin pain and discomfort with occasional parathesia around the incision line and foreign body sensation in the groin. These pains lasted for 8 and 10 weeks post operatively. Fortunately, it did not adversely affect the quality of life of these patients and reassurance was enough. No cases of such groin pains were recorded in the TEP group. At the three months postoperative visit, all patients of both groups returned to their usual ordinary activity and were pain and recurrence free. Follow up continued at six and 12 moths postoperatively without new events. We had two cases of recurrence among group A patients during follow up period of 6 months.

\section{CONCLUSION}

It could be concluded that both open and TEP techniques are considered safe as all perioperative complications are well tolerated by patients and there was no need for a second operative intervention. However intraoperative complications with open group were significantly higher than TEP group, more vascular and visceral injuries while TEP group more peritoneal tears and conversion. In the current study, open repair is a much easier procedure with steeper learning curve in contrast to the TEP repair which appeared technically more difficult as evidenced by increased operative time, conversion, and secondary bleeding. Patients treated by TEP repair suffered more acute postoperative pain as expressed by lower pain scores and analgesic consumption.

TEP repair was associated with shorter hospital stay and rapid return to normal activity. Our data suggested TEP being extra-peritoneal repair is comparatively safe whereas open on the other hand offers good visualization of and easy learning curve. However, furthermore targeted wider scale studies are recommended. Both techniques are effective in the management of inguinal hernia and were associated with $0 \%$ recurrence. However, due to small sample size and short follow up duration, longer- term studies are also recommended.

\section{REFERENCES}

1. Bay-Nielsen M, Kehlet H, Strand L et al. (2001): Quality assessment of 26,304 herniorrhaphies in Denmark: a prospective nationwide study. Lancet, 358:1124-1128.

2. Van der Pool A, Harlaar J, den Hoed T et al. (2010): Long-term follow-up evaluation of chronic pain after endoscopic total extraperitoneal repair of primary and recurrent inguinal hernia. Surg Endosc., 24(7):1707-11.

3. Eklund A, Carlsson P, Rosenblad A et al. (2010): Longterm cost-minimization analysis comparing laparoscopic 
with open (Lichtenstein) inguinal hernia repair. The British Journal of Surgery, 97(5): 765-71.

4. Hallén M, Bergenfelz A, Westerdahl J (2008): Laparoscopic extraperitoneal inguinal hernia repair versus open mesh repair: long-term follow-up of a randomized controlled trial. Surgery, 143(3):313-7.

5. Bittner R, Schwarz J (2012): Inguinal hernia repair: current surgical techniques. Langenbecks Arch Surg., 397(2):271-82.

6. Morales-Conde S (2016): Complications After Total Endoscopic Preperitoneal (TEP) Repair. In: Avci C., Schiappa J. (eds) Complications in Laparoscopic Surgery. Springer, Cham. https://basicmedicalkey.com/complications-after-totalendoscopic-preperitoneal-tep-repair/

7. Salma U, Ahmed I, Ishtiaq S et al. (2015): A comparison of postoperative pain and hospital stay between Lichtenstein's repair and Laparoscopic Transabdominal Preperitoneal (TAPP) repair of inguinal hernia: A randomized controlled trial. Pak J Med Sci., 31(5):10621066.

8. Loos M, Houterman S, Scheltinga M et al. (2008): Evaluating postherniorrhaphy groin pain: Visual Analogue or Verbal Rating Scale? Hernia, 12(2):147-51.

9. Eklund A, Rudberg C, Smedberg S et al. (2006): Shortterm results of a randomized clinical trial comparing Lichtenstein open repair with totally extraperitoneal laparoscopic inguinal hernia repair. British Journal of Surgery, 93:1060-1068.

10. Campanelli G, Bertocchi V, Cavalli M et al. (2013): Surgical treatment of chronic pain after inguinal hernia repair. Hernia, 17(3):347-53.

11. IBM Corp. (2016): Released 2016. IBM SPSS Statistics for Windows, Version 24.0. Armonk, NY: IBM Corp. https://www.ibm.com/support/pages/how-cite-ibm-spssstatistics-or-earlier-versions-spss

12. Vidović D, Kirac I, Glavan E et al. (2007): Laparoscopic Totally Extraperitoneal Hernia Repair Versus Open Lichtenstein Hernia Repair: Results and Complications. Journal of Laparoendoscopic \& Advanced Surgical Techniques, 7: 585-590.

13. Liem M, Duyn E, Graaf Y et al. (2003): Recurrences after conventional anterior and laparoscopic inguinal hernia repair: a randomized comparison. Annals of Surgery, 237(1): 136-41.

14. Bringman S, Ramel S, Heikkinen T et al. (2003): Tensionfree inguinal hernia repair: TEP versus mesh-plug versus Lichtenstein: a prospective randomized controlled trial. Ann Surg., 237(1):142-7.

15. Lancet (1999): Laparoscopic versus open repair of groin hernia: a randomised comparison. The MRC Laparoscopic Groin Hernia Trial Group. Lancet, 354(9174):185-90.

16. Gong K, Zhang N, Lu Y et al. (2011): Comparison of the open tension-free mesh-plug, transabdominal preperitoneal (TAPP), and totally extraperitoneal (TEP) laparoscopic techniques for primary unilateral inguinal hernia repair: a prospective randomized controlled trial. Surg Endosc., 25(1):234-9.

17. Schouten $\mathbf{N}$, Simmermacher $\mathrm{R}$, van Dalen $\mathrm{T}$ et al. (2013): Is there an end of the "learning curve" of endoscopic totally extraperitoneal (TEP) hernia repair? Surg Endosc., 27: 789-794.

18. Kim B, Duh Q (2009): Surgical pitfalls Laparoscopic Inguinal Hernia Repair. J Laparoendosc Adv Surg Tech A., 51:514-521.

19. Putnis S, Berney C (2012): Totally extraperitoneal repair of inguinal hernia: techniques and pitfalls of a challenging procedure. Langenbecks Arch Surg., 397: 1343-1351.

20. Cohen R, Schiavon C, Roll S et al. (2003): Complications and their management. In: Laparoscopic hernia surgery an operative guide. First edition. Edited by Karl A. Le Blanc, 12:89-95.

21. Wang W, Chen J, Fang Q et al. (2013): Comparison of the effects of laparoscopic hernia repair and lichtenstein tension- free hernia repair. J Laparoendosc Adv Surg Tech A., 23(4): 301-5.

22. Voeller G (2004): Inguinal Hernia Repair. In: Management of Laparoscopic Surgical Complications, first edition. Edited by Leblanc K.A., Marcel Dekker, Pp. 15: 277-284.

23. Sanchez-Manuel F, Lozano-García J, Seco-Gil J (2012): Antibiotic prophylaxis for hernia repair. Cochrane Database of Systematic Reviews, 2: 3769-74.

24. Aufenacker T, Koelemay M, Gouma D et al. (2006): Systematic review and meta-analysis of the effectiveness of antibiotic prophylaxis in prevention of wound infection after mesh repair of abdominal wall hernia. Br J Surg., 93(1):510 .

25. Köckerling F, Bittner R, Jacob D et al. (2015): Do we need antibiotic prophylaxis in endoscopic inguinal hernia repair? Results of the Herniamed Registry. Surg Endosc., 29(12):3741-9.

26. Lepere M, Benchetrit S, Debaert $M$ et al. (2000): Multicentric comparison of transabdominal versus totally extraperitoneal laparoscopic hernia repair using PARIETEX meshes. Journal of the Society of Laparoendoscopic Surgeons, 4(2):147-53.

27. Nowobilski W, Dobosz M, Wojciechowicz T et al. (2004): Lichtenstein inguinal hernioplasty using butyl-2cyanoacrylate versus sutures. Preliminary experience of a prospective randomized trial. Eur Surg Res., 36:367-70.

28. Khajanchee Y, Urbach D, Swanstrom L et al. (2001): Outcomes of laparoscopic herniorrhaphy without fixation of mesh to the abdominal wall. Surg Endosc., 15(10):11021107.

29. Stark E, Oestreich K, Wendl K et al. (1999): Nerve irritation after laparoscopic hernia repair. Surg Endosc., 13(9):878-881.

30. Baca I, Schultz C, Gotzen V et al. (2000): Laparoscopic inguinal hernia repair. A review of 2500 cases. Proceedings of the 7th World Congress of Endoscopic Surgery, 10: 42530.

31. McCormack K, Scott N, Go P et al. (2003): Laparoscopic techniques versus open techniques for inguinal hernia repair. Cochrane Database Syst Rev., 1: 777-785.

32. Nienhuijs $\mathbf{S}$, Staal E, Strobbe L et al. (2007): Chronic pain after mesh repair of inguinal hernia: a systematic review. Am J Surg., 194(3): 394-400. 